\title{
54. PRELIMINARY REPORT ON THE MAGNETIC FABRIC OF APTIAN AND ALBIAN LIMESTONES FROM THE MID-PACIFIC MOUNTAINS AND HESS RISE, DRILLED DURING DEEP SEA DRILLING PROJECT LEG $62^{1}$
}

\author{
William O. Sayre, ${ }^{2}$ Oceanography Department, University of Southampton, \\ Southampton, $\mathrm{SO} 95 \mathrm{NH}$ England
}

\begin{abstract}
The magnetic fabric of Aptian and Albian limestones from Deep Sea Drilling Project Hole 463, on the Mid-Pacific Mountains in the central Pacific, is characterized by a well-defined foliation plane dipping a few degrees from the horizontal towards the east-northeast.This may represent a slightly dipping depositional surface, or it may be the result of off-vertical drilling. Variable maximum susceptibility directions and $q$ parameter values less than 0.06 indicate a poorly developed magnetic lineation, probably due to the lack of significant bottom currents at the time of deposition. At Hole $465 \mathrm{~A}$, on the Hess Rise, also in the central Pacific, late Albian limestones carry a very weak magnetic fabric because of the lack of magnetic minerals in these sediments.
\end{abstract}

\section{INTRODUCTION}

In the summer of 1978, Glomar Challenger occupied four sites on two major aseismic rises in the central Pacific Ocean-the Mid-Pacific Mountains and Hess Rise. The major objectives of drilling included a study of Mesozoic and Cenozoic paleoenvironments and an investigation into the origin of the two rises.

Magnetic-fabric measurements were carried out at Holes 463 and $465 \mathrm{~A}$ to investigate the possible existence of depositional slopes and paleocurrent activity.

\section{THE MAGNETIC-FABRIC TECHNIQUE}

Magnetic susceptibility $\left(K_{i j}\right)$ relates intensity of magnetization in a direction $i\left(J_{i}\right)$ to the strength of an applied field in a direction $j\left(H_{j}\right)$, according to the equation

$$
J_{i}=K_{i j} H_{j}
$$

The magnetic fabric of a sediment is defined by the anisotropy of magnetic susceptibility (AMS), i.e., the variation of susceptibility with direction. In purely isotropic material, $K_{i j}$ is constant but many rocks are magnetically anisotropic, usually because of a preferred orientation of elongate magnetic grains (shape anisotropy). This AMS can be modeled by a second-order tensor with three principal axes of susceptibility, the maximum, intermediate, and minimum axes $\left(K_{\max }, K_{\text {int }}\right.$, and $K_{\min }$, respectively). For shape anisotropy, the AMS tensor mimics the preferred orientation of the total assemblage of magnetic grain shapes within a rock sample. Combined optical and magnetic studies have confirmed that the magnetic and non-magnetic fractions of a sediment have similar orientations, and that the $K_{\max }$ axis parallels the direction of preferred orientation of

\footnotetext{
1 Initial Reports of the Deep Sea Drilling Project, Volume 62. 50011 .

2 Initial Reports of the Deep Sea Drilling Project, Volume 62.
Present address: Department of Earth Sciences, Iowa State University, Ames, lowa
}

elongate grains (e.g., Rees, 1965; Asahiko and Lienert, 1979).

The magnetic-fabric measurements presented in this report were made on a low-field torque magnetometer, or LFTM (as described by King and Rees, 1962), in an applied field of $100 \mathrm{Oe}$, and all bulk susceptibilities were measured on a balanced alternating-current bridge.

The $K_{\max }$ axis defines the direction of the magnetic lineation, and the plane containing the $K_{\max }$ and $K_{\text {int }}$ axes represents the magnetic foliation plane, with the $K_{\min }$ axis at its pole.

The azimuthal anisotropy quotient, $q$ (Rees, 1966), represents the relative strengths of magnetic lineation and foliation:

$$
q=\frac{K_{\max }-K_{\mathrm{int}}}{\left(K_{\max }+K_{\mathrm{int}}\right) / 2-K_{\min }}
$$

It varies from 0.0 for pure foliation to 2.0 for pure lineation. Another parameter often used to study fabric is the percentage of anisotropy, $h$, which gives an indication of the overall strength of anisotropy:

$$
h=\frac{100\left(K_{\max }-K_{\min }\right)}{K_{\text {int }}}
$$

\section{MAGNETIC FABRIC OF SEDIMENTS}

An undeformed sedimentary fabric can be characterized by a gravity-controlled foliation and, when hydraulic shear is present, a current-controlled lineation (for a review, see Hamilton and Rees, 1970). The $K_{\max }$ axis usually parallels the current direction, as verified by comparison with a variety of features such as sole markings, small-scale cross-bedding, imbricated pebbles, and channel axes (Hamilton, 1963; Rees, 1965; Galehouse, 1968; Rees, 1970). In addition, $K_{\max }$ axes have been reported to be imbricated, i.e., to dip downward at a slight angle into the direction of current flow (Rees, 1965; Rees and Woodall, 1975). In principle, this can allow for the identification of the azimuth of flow from 
the upward-directed end of the $K_{\max }$ axis. However, a dipping $K_{\max }$ axis can also be produced by deposition in still water onto a slope (Rees, 1966). In this case, the magnetic foliation plane will have a strike similar to that of the bedding plane and will dip at a slightly smaller angle, and the $K_{\max }$ direction will parallel the direction of dip.

Laboratory flume experiments have been carried out to study the acquisition of magnetic fabric and how it relates to grain size (Rees, 1961; Hamilton, 1967; Hamilton et al., 1968; Rees and Woodall, 1975). The orientation of fine silt and clay-sized particles was found to be controlled by magnetic forces, the direction of remanent magnetization being aligned parallel with the ambient geomagnetic field. It was coarser silt and sand that recorded a current lineation and gravity foliation. Post-depositional rotation also probably serves to orient the smaller magnetic particles with the geomagnetic field (L $\phi$ vlie, 1974, 1976).

Thus, it is possible that both a remanence paralleling the geomagnetic field and a depositional magnetic fabric can be accurately recorded in a sediment when a range of grain sizes is present. This is a major assumption in the study of magnetic fabric in unoriented drill cores: if the remanence was acquired during deposition (or through post-depositional rotation) and secular variation is properly averaged out, the declination of remanent magnetization for each sample should point to the magnetic north pole. By plotting the AMS axes relative to the declination of stable remanence (or, as referred to in this report, mean magnetic north$\mathrm{MMN}$ ), it is possible to specify $K_{\max }$ and $K_{\min }$ directions relative to geographic north at the time of sediment deposition.

Orientation of fabric data using the remanence direction after demagnetization has been successfully applied in recent studies (Hailwood and Sayre, 1979; Hamilton, 1979). These and studies of unoriented marine sediments (Rees, 1971; Rees and Frederick, 1974) have shown that terrigenous sediments are more likely to acquire a depositional fabric, and that largely pelagic sediments (specifically oozes and deep-sea clays) carry either a weak or deformed fabric. However, limestones can be expected to have a measurable fabric (Turner 1975). When present, a gravity-produced foliation was found to dominate a very weak lineation in most of these marine sediments, although Hamilton (1979) reported a well-defined lineation paralleling inferred bottom currents. Curie-point analyses indicated that the magnetic constituent in the sediment was magnetite, confirming that the fabric arose from shape anisotropy.

\section{RESULTS}

Thirty-eight samples from Cores 57 to 76 from DSDP Hole 463 have been measured. They came from three lithologic units: lower Albian to Aptian multicolored limestones, (Cores 57 to 66), lower Aptian tuffaceous and carbonaceous limestones, (Cores 67 to 71), and lower Aptian pelagic and clastic limestones (Cores 72 to 76), (Site 463 report, this volume). Clastic layers in the oldest unit represent shallow-water stromatolite, oolite, and mollusk debris redeposited at depths below wave base. Subsidence has carried the site to its present depth of 2500 meters, but deposition has always occurred above the carbonate-compensation depth. Average sedimentation rates in the Aptian and Albian were 27 and 12 m./m.y., respectively, uncorrected for compaction.

The thermomagnetic curve of a representative limestone sample exhibits a Curie point between 550 and $600^{\circ} \mathrm{C}$, indicative of titanomagnetite with a low titanium content (Fig. 1). This mineral is crystallographically isotropic, and the bulk sediment fabric can be interpreted as arising from grain-shape effects.

$K_{\max }$ and $K_{\min }$ directions from Hole 463 presented in Figures 2A and 2D are plotted relative to each sample's $\mathrm{Z}$ or cylindrical axis, in the position that each was in the drill hole, with no azimuthal orientation between samples. Thus, they should show a random azimuthal distribution reflecting the unoriented nature of the drill core. Instead, $K_{\min }$ directions are well grouped, with "southwesterly" declinations, and $K_{\max }$ axes take up a "northwest-southeast" lineation. These directions are very similar to those of the LFTM's background noise, i.e., the susceptibility tensor calculated from measurements made without any sample present.

A noise correction can be made by subtracting the signal due to the background noise from the measurements of each sample. Afterward, it can be seen that $K_{\min }$ directions take up a more random distribution near the vertical, representing a near horizontal foliation plane (Figs. $2 \mathrm{E}$ and 3 ), but $K_{\max }$ directions still retain a vague lineation, now oriented "north-south"' (Figs. 2B and 3).

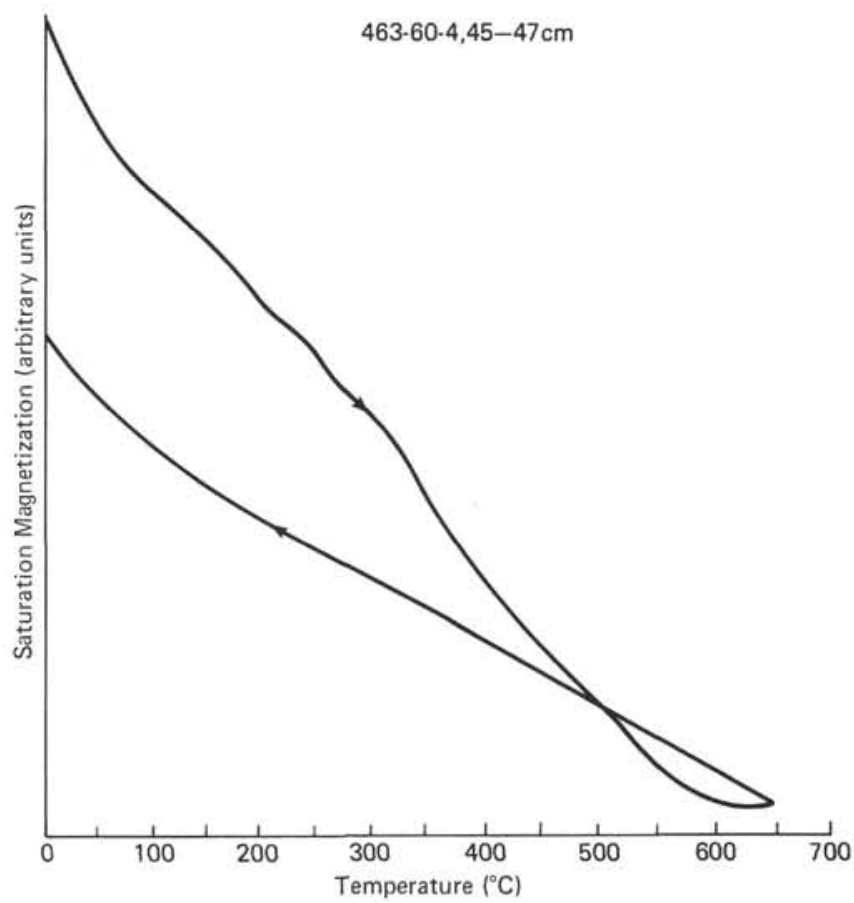

Figure 1. Thermomagnetic curve for Sample 463-60-4, 45-47 cm. Arrows indicate heating-cooling cycle. 

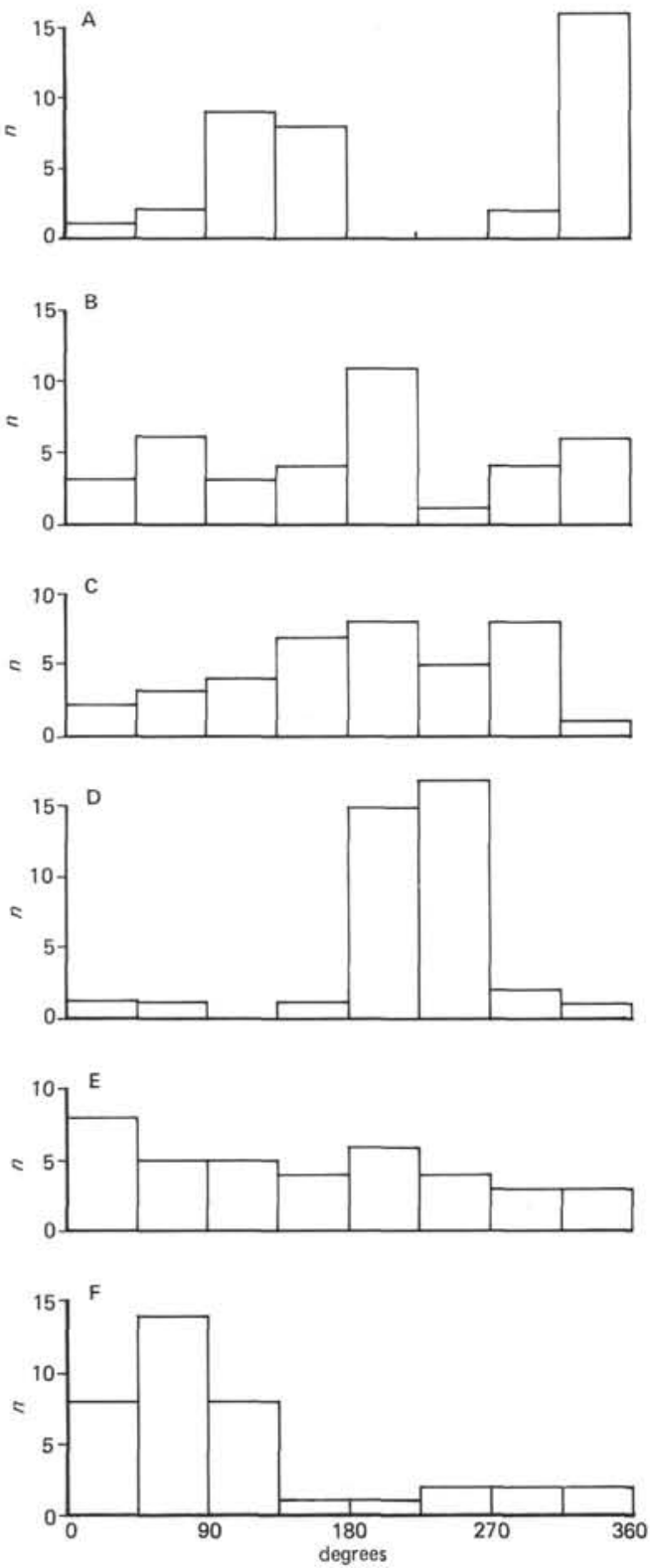

Figure 2. Histograms of number of samples versus azimuth for samples from Hole 463 . A. $K_{\max }$ relative to $\mathrm{Z}$ before noise correction. B. $K_{\max }$ relative to $\mathrm{Z}$ after noise correction. C. $K_{\max }$ relative to $\mathrm{MMN}$ after noise correction. D. $K_{\min }$ relative to $\mathrm{Z}$ before noise correction. E. $K_{\min }$ relative to $\mathrm{Z}$ after noise correction. F. $K_{\min }$ relative to $\mathrm{MMN}$ after noise correction. See text.

After the remanence correction, using directions after demagnetization (Figs. $2 \mathrm{~F}$ and 4 ), a significant increase in the grouping of $K_{\min }$ directions occurs (represented by an increase in Fisher's precision parameter, $k$, from 25.9 to 29.8 ), with a mean east-northeast direction. A lack of grouping of $K_{\max }$ directions after the remanence correction (Figs. $2 \mathrm{C}$ and 4 ) is thought to indicate that the magnetic lineation is very weak and poorly defined in these samples. This correlates with low $q$ values of less than 0.06 (Table 1). The "northsouth" lineation could represent some further bias in

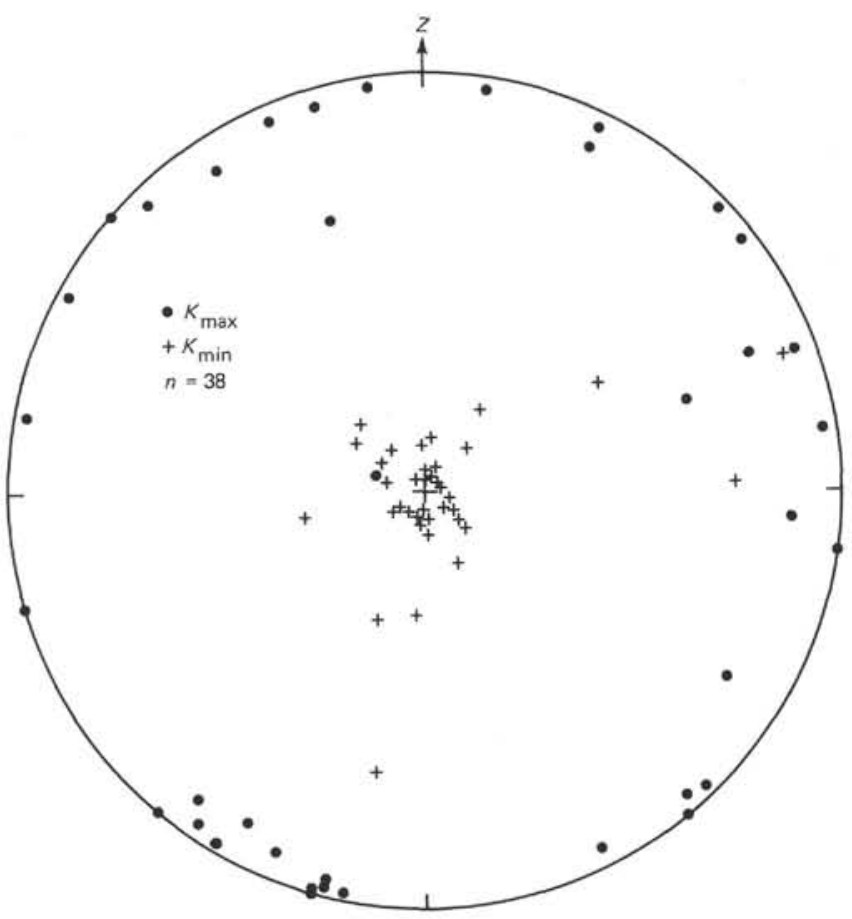

Figure 3. Equal-area stereographic projection of $K_{\max }$ and $K_{\min }$ axes of limestone samples from Hole 463. Upper hemisphere. Each sample has been plotted relative to its own " $\mathrm{Z}$ " or cylindrical axis, i.e., in its position in the drill hole, but with no azimuthal orientation between samples. Directions are after the noise correction.

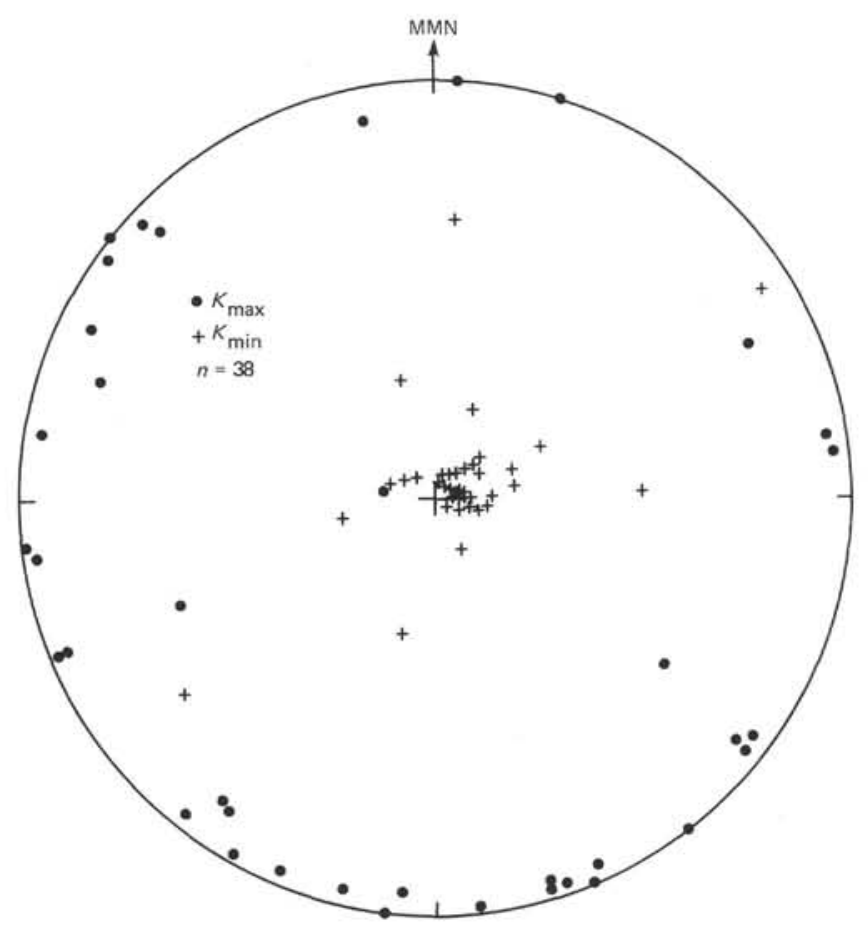

Figure 4. $K_{\max }$ and $K_{\min }$ axes of limestone samples from Hole 463 , plotted relative to mean magnetic north (MMN), defined by directions of stable remanence in each sample. Same projection and symbols as in Figure 3. After noise correction. 
Table 1. Hole 463 magnetic-fabric results, after noise and remanence corrections. See text for explanation of symbols.

\begin{tabular}{|c|c|c|c|c|c|c|c|c|}
\hline \multirow{2}{*}{$\begin{array}{c}\text { Sample } \\
\text { (interval in } \mathrm{cm} \text { ) }\end{array}$} & \multirow{2}{*}{$\begin{array}{l}\text { Sub-bottom } \\
\text { Depth } \\
\text { (m) }\end{array}$} & \multicolumn{2}{|c|}{$K_{\max }$} & \multicolumn{2}{|c|}{$K_{\min }$} & \multirow[b]{2}{*}{$q$} & \multirow[b]{2}{*}{$\Sigma G \%$} & \multirow[b]{2}{*}{$H$} \\
\hline & & Dec. & Inc. & Dec. & Inc. & & & \\
\hline $463-57-1,133-135 a$ & 500.84 & 263 & -1 & 130 & -88 & 0.16 & 9.0 & 1.01 \\
\hline $57-1,133-135 b$ & & 111 & -3 & 346 & -84 & 0.13 & -10.0 & 0.90 \\
\hline $57-2,26-28$ & 501.27 & 158 & 0 & 70 & -85 & 0.05 & -6.0 & 1.94 \\
\hline $57-2,66-68 a$ & 501.67 & 75 & -5 & 295 & -82 & 0.24 & -105.0 & 1.03 \\
\hline $57-2,66-68 \mathrm{~b}$ & & 87 & -5 & 301 & -83 & 0.055 & -35.0 & 0.94 \\
\hline $58-1,5-7$ & 509.06 & 262 & -3 & 121 & -85 & 0.04 & 10.0 & 1.67 \\
\hline $58-2,83-85$ & 511.34 & 3 & 0 & 77 & -86 & 0.02 & -4.0 & 1.88 \\
\hline $59-2,100-102$ & 521.01 & 219 & -4 & 97 & -80 & 0.03 & -35.0 & 1.10 \\
\hline $59-3,147-149$ & 522.98 & 314 & -9 & 82 & -75 & 0.07 & 13.0 & 1.20 \\
\hline $59-4,15-17$ & 523.16 & 194 & -4 & 28 & -85 & 0.04 & 79.0 & 0.69 \\
\hline $59, \mathrm{CC}, 4-6$ & 523.35 & 306 & -3 & 79 & -84 & 0.02 & 15.0 & 0.79 \\
\hline $60-2,27-29$ & 529.78 & 163 & -2 & 59 & -81 & 0.03 & 3.0 & 1.97 \\
\hline $60-4,45-47$ & 532.96 & 174 & -1 & 47 & -87 & 0.04 & -2.0 & 2.47 \\
\hline $61-1,52-54$ & 536.03 & 313 & -4 & 90 & -83 & 0.08 & 36.0 & 0.53 \\
\hline $61-1,76-78$ & 536.27 & 247 & -4 & 86 & -85 & 0.04 & 0.0 & 0.91 \\
\hline $62-1,5-7$ & 537.56 & 17 & 0 & 91 & -86 & 0.05 & 38.0 & 1.11 \\
\hline $62-1,125-127$ & 538.76 & 349 & -9 & 152 & -79 & 0.02 & -42.0 & 0.70 \\
\hline $62-2,82-84$ & 539.83 & 161 & -2 & 8 & -87 & 0.10 & 41.0 & 0.76 \\
\hline $62-3,112-114$ & 541.63 & 203 & -3 & 14 & -86 & 0.03 & 7.0 & 0.70 \\
\hline $63-1,82-84$ & 547.82 & 163 & -3 & 43 & -82 & 0.09 & 13.0 & 1.08 \\
\hline $63-3,12-14$ & 550.13 & 143 & 0 & 48 & -81 & 0.19 & 123.0 & 0.74 \\
\hline $63, \mathrm{CC}, 23-25$ & 53. 74 & 214 & -11 & 47 & -78 & 0.14 & 58.0 & 0.62 \\
\hline $64-1,2-4$ & 556.53 & 129 & -7 & 286 & -81 & 0.23 & 116.0 & 0.93 \\
\hline $64-1,5-7$ & 556.56 & 129 & -4 & 317 & -85 & 0.23 & 12.0 & 0.98 \\
\hline $64-1,9-11$ & 556.60 & 156 & -4 & 260 & -72 & 0.94 & 304.0 & 0.60 \\
\hline $64-1,21-23$ & 556.72 & 210 & -2 & 100 & -83 & 0.29 & 41.0 & 0.95 \\
\hline $64-2,15-17$ & 558.16 & 247 & -2 & 34 & -87 & 0.07 & 100.0 & 0.49 \\
\hline $65-2,21-23$ & 567.72 & 279 & -5 & 85 & -84 & 0.059 & 64.0 & 0.61 \\
\hline $66-1,17-19$ & 575.68 & 289 & -16 & 65 & -67 & 0.74 & 266.0 & 0.24 \\
\hline $66-2,21-23$ & 577.22 & 247 & -34 & 5 & -33 & 1.15 & -108.0 & 0.29 \\
\hline $66-3,35-37$ & 578.86 & 185 & -5 & 89 & -48 & 0.42 & 511.0 & 0.19 \\
\hline $67-1,128-130$ & 586.29 & 309 & 0 & 40 & -84 & 0.09 & 174.0 & 0.36 \\
\hline $67-2,120-122$ & 587.71 & 296 & -9 & 90 & -79 & 0.03 & 62.0 & 0.51 \\
\hline $69-2,134-136$ & 606.85 & 187 & 0 & 105 & -82 & 0.08 & 38.0 & 0.67 \\
\hline $70-4,30-32$ & 618.31 & 127 & -4 & 22 & -71 & 0.39 & 13.0 & 0.78 \\
\hline $71-2,77-79$ & 625.28 & 277 & -80 & 58 & -7 & 0.75 & 14.0 & 0.38 \\
\hline $72-3,80-82$ & 636.31 & 216 & -12 & 70 & -74 & 0.40 & 31.0 & 1.57 \\
\hline $73-2,91-93$ & 644.42 & 83 & -3 & 345 & -66 & 0.51 & 71.0 & 1.07 \\
\hline $75-1,35-37$ & 661.36 & 64 & -17 & 195 & -63 & 0.47 & 101.0 & 1.30 \\
\hline $76-1,63-65$ & 671.14 & 126 & -32 & 233 & -25 & 0.48 & 200.0 & 2.11 \\
\hline
\end{tabular}

the data (such as weak sample-shape effects), not present in the $K_{\min }$ results, because of the relatively stronger foliation.

Values of $h$ average approximately $1.0 \%$ (Table 1), which is common in sediments. The parameter $\Sigma G \%$ falls within the acceptable range for shape effects, -40.0 to 40.0 (Table 1 ). Higher values indicate morecomplex anisotropy.

Ten samples of the late Aptian laminated limestones from Hole 465A have also been measured (Table 2). The lowest section of this unit, which directly overlies a weathered trachyte sequence, contains shallow-water debris redeposited at a depth of a few hundred meters (Site 465 report, this volume). The site subsided to typical continental-slope depths by the end of the late Albian. Deposition occurred at an average rate of 58 m./m.y., uncorrected for compaction.

Table 2. Hole 465A magnetic-fabric results, after noise and remanence corrections. See text for explanation of symbols.

\begin{tabular}{|c|c|c|c|c|c|c|c|c|}
\hline \multirow{2}{*}{$\begin{array}{c}\text { Sample } \\
\text { (interval in } \mathrm{cm} \text { ) }\end{array}$} & \multirow{2}{*}{$\begin{array}{l}\text { Sub-bottom } \\
\text { Depth } \\
\text { (m) }\end{array}$} & \multicolumn{2}{|c|}{$K_{\max }$} & \multicolumn{2}{|c|}{$K_{\min }$} & \multirow[b]{2}{*}{$q$} & \multirow[b]{2}{*}{$\Sigma G \%$} & \multirow[b]{2}{*}{$H$} \\
\hline & & Dec. & Inc. & Dec. & Inc. & & & \\
\hline $65 \mathrm{~A}-26-1,52-54$ & 277.03 & 333 & -22 & 165 & -67 & 0.34 & 445.0 & 2.82 \\
\hline $27-1,71-73$ & 286.72 & 282 & -17 & 45 & -59 & 1.41 & 508.0 & 0.62 \\
\hline $28-1,112-114$ & 296.63 & 138 & -8 & 21 & -72 & 0.59 & 40.1 & 14.72 \\
\hline $29-1,88-90$ & 305.89 & 182 & -9 & 8 & -80 & 0.19 & 55.0 & 2.51 \\
\hline $31-1,32-34$ & 324.33 & 167 & -3 & 76 & -24 & 1.72 & 59.0 & 1.28 \\
\hline $32-1,108-110$ & 334.59 & 353 & -78 & 125 & -7 & 0.34 & 108.0 & 4.18 \\
\hline $34-1,47-49$ & 352.98 & 10 & -18 & 242 & -60 & 0.52 & 502.0 & 0.70 \\
\hline $37-1,71-73$ & 381.72 & 285 & -29 & 73 & -56 & 0.38 & 500.0 & 1.46 \\
\hline $38-2,95-97$ & 392.96 & 132 & -35 & 253 & -35 & 0.45 & 526.0 & 1.85 \\
\hline $39-2,85-87$ & 402.30 & 22 & -2 & 113 & -11 & 1.18 & 531.0 & 3.00 \\
\hline
\end{tabular}

$K_{\max }$ and $K_{\min }$ inclinations are variable and not grouped in the horizontal or vertical, and noise and remanence corrections do not decrease the scatter in the results (Figs. 5 and 6 ). All $\Sigma G \%$ values fall outside the accepted limits, and $q$ values average $0.71 \pm 0.53$ (Table 2). In addition, susceptibility values for some of the samples were extremely low (less than $10^{-5}$ emu/Oe bulk susceptibility), and some had negative susceptibilities indicative of a complete lack of ferro- or ferrimagnetic minerals.

\section{DISCUSSION}

The azimuthal orientation of the Hole 463 data produces a grouping of $K_{\min }$ directions offset from the vertical towards the east-northeast. This offset may be due to off-vertical drilling in Cores 57 to 76 , but because no dip meter runs were made in the hole this cannot be verified. Alternatively, the Aptian-Albian depositional surface could be striking north-northwest and dipping east-northeast. The lack of a lineation suggests the absence of persistent bottom currents at the site during this time. This is consistent with deposition in a quiet environment, where no orienting forces other than gravity would be expected to act on the sedimentary particles.

A factor that contributes to the scatter of $K_{\max }$ and $K_{\text {min }}$ directions is geomagnetic secular variation. Each sample probably represents less than 10,000 years of deposition, the time interval over which secular variation is normally considered to be averaged. If this is the case, remanence declinations could differ by as much as 20 to $30^{\circ}$ from geographic north, imparting the same er-

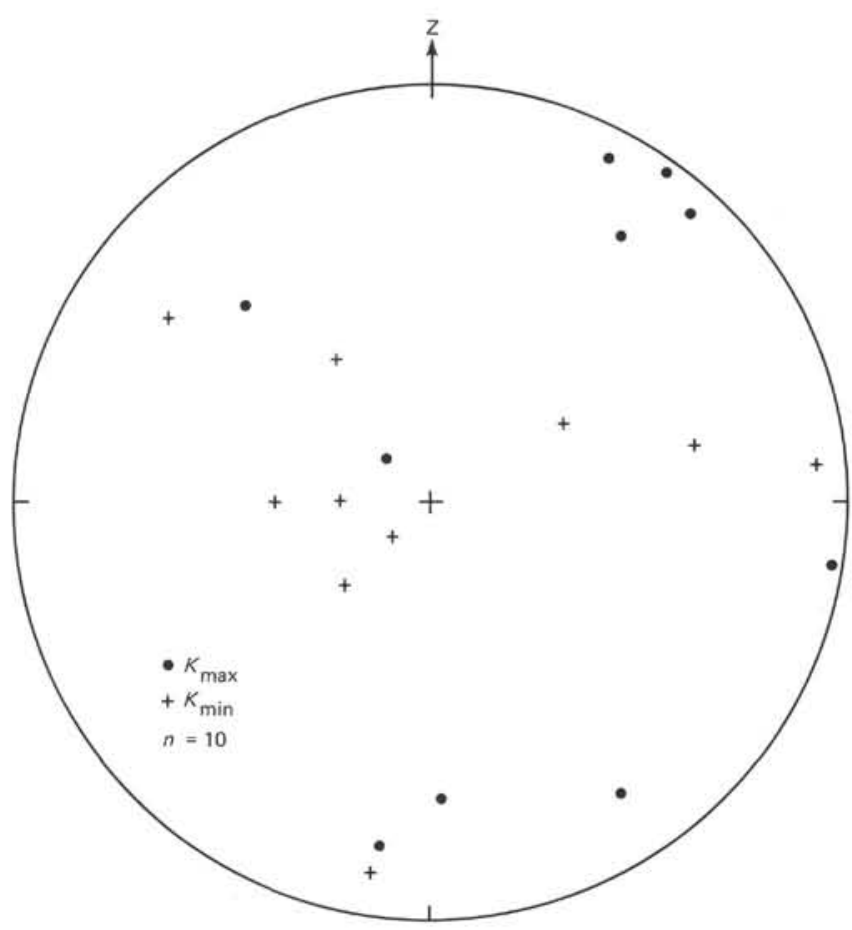

Figure 5. $K_{\max }$ and $K_{\min }$ axes of limestone samples from Hole $465 \mathrm{~A}$, plotted relative to the " $Z$ " axis. Same projection and symbols as in Figure 3. After noise correction. 


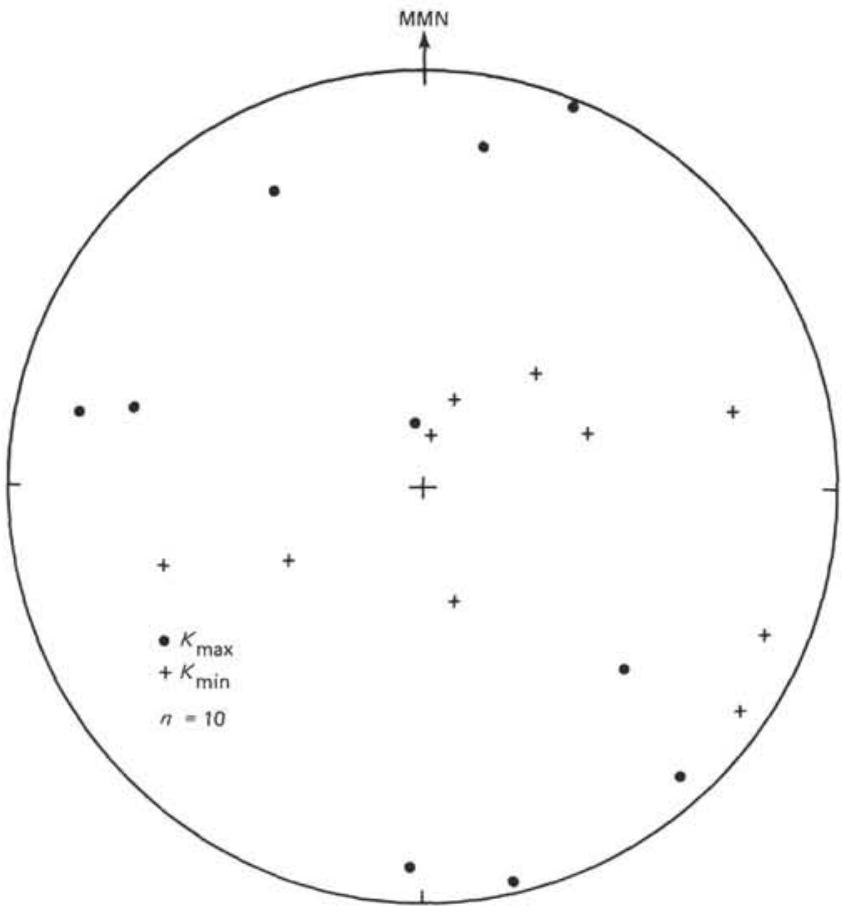

Figure 6. $K_{\max }$ and $K_{\min }$ axes of limestone samples from Hole 465A, plotted relative to MMN. Same projection and symbols as in Figure 3. After noise correction.

ror to the azimuths of the susceptibility axes after orientation.

A well-defined stable component of magnetization has been identified in almost all these samples (Sayre, this volume). Most directions are reliable to within $5^{\circ}$, judging from the results of demagnetization, and a few are reliable to within $15^{\circ}$, indicating that secondary components are probably not present in the data.

Samples with $K_{\max }$ and $K_{\min }$ axes showing large departures from the horizontal and vertical, respectively, probably carry a secondary fabric formed by such processes as soft-sediment deformation or bioturbation.

The magnetic fabric of the Hole 465A limestones is weak and indistinct and was probably not acquired during deposition. This is indicated by the average $q$ value, near 0.67 , showing that the fabric tensor is nearly triaxial and anisotropy is almost non-existent, with no foliation or lineation. These results contrast with those for the Hole 463 limestones, in that $q$ values are higher and there is no foliation. This is probably due to the relative scarcity of magnetic minerals in the Hole $465 \mathrm{~A}$ samples. The lack of foliation indicates the absence of a gravitational orienting couple which could correlate with finer grain sizes, although no quantitative grain-size analyses are now available.

\section{ACKNOWLEDGMENTS}

This paper benefited from constructive reviews by E. A. Hailwood and P. W. Plumley. The diagrams were drafted by Trisha Badham, and the final draft of the manuscript was typed by Jane Windom. Financial support came from the U. K. Natural Environment Research Council.

\section{REFERENCES}

Asahiko, T., and Lienert, B. R., 1979. The comparative reliability of magnetic, photometric, and microscopic methods of determining the orientation of sedimentary grains. J. Sediment. Petrol., 49: 759-772.

Galehouse, J. S., 1968. Anisotropy of magnetic susceptibility as a paleocurrent indicator: a test of the method. Geol. Soc. Am. Bull., 79:387-390.

Hailwood, E. A., and Sayre, W. O., 1979. Magnetic anisotropy and sediment transport directions in North Atlantic Early Cretaceous black shales and Eocene mudstones cored on DSDP Leg 48. In Montadert, L., Roberts, D. G., et al., Init. Repts. DSDP, 48: Washington (U. S. Govt. Printing Office), 909-918.

Hamilton, N., 1963. Susceptibility anisotropy measurements on some Silurian siltstones. Nature, 197:170-171. 1967. Laboratory redeposition studies - an appraisal of apparatus and technique. In Collinson, D. W., et al. (Eds.), Methods in Palaeomagnetism: Amsterdam (Elsevier), pp. 596-603. 1979. Preliminary magnetic fabric studies of Lower Cretaceous sediments from DSDP Site 397, northwest African continental margin. In von Rad, U., Ryan, W. B. F., et al., Init. Repts. DSDP, 47, Pt. 1: Washington (U.S. Govt. Printing Office), 481-482.

Hamilton, N., Owens, W. H., and Rees, A. I., 1968. Lab experiments on the production of grain orientation in shearing sands. J. Geol., $76: 465-472$.

Hamilton, N., and Rees, A. 1., 1970. The use of magnetic fabric in palaeocurrent estimation. In Runcorn, S. K. (Ed.), Palaeogeophysics: New York (Academic Press), pp. 445-464.

King, R. F., and Rees, A. I., 1962. The measurement of the anisotropy of magnetic susceptibility of rocks by the torque method. J. Geophys. Res., 67:1565-1572.

L $\phi$ vlie, R., 1974. Post-depositional remanent magnetization in a redeposited deep-sea sediment. Earth Planet. Sci. Lett., 21: 315-320.

1976. The intensity pattern of post-depositional remanence acquired in some marine sediments deposited during a reversal of the external magnetic field. Earth Planet. Sci. Lett., 30:209-214.

Rees, A. I., 1961. The effect of water currents on the magnetic remanence and anisotropy of susceptibility of some sediments. Geophys. J. Royal Astr. Soc., 5:235-251.

, 1965. The use of anisotropy of magnetic susceptibility in the estimation of sedimentary fabric. Sedimentology, 4:257-271.

1966. The effect of depositional slopes on the anisotropy of magnetic susceptibility of lab deposited sands. J. Geol., 74: 856-867.

1970. Magnetic properties of some canyon sediments. Mar. Geol., 9:M12-M16.

, 1971. The magnetic anisotropy of samples from DSDP Leg 1, Orange, Texas to Hoboken, New Jersey. Mar. Geol., 11: M16-M123.

Rees, A. I., and Frederick, D, 1974. The magnetic fabric of sediments from the Deep Sea Drilling Project, Legs I-VI. J. Sediment. Petrol., 44:655-662.

Rees, A.I., and Woodall, W. A., 1975. The magnetic fabric of some lab-deposited sediments. Earth Planet. Sci. Lett., 25:121-130.

Turner, P., 1975. Depositional magnetization of Carboniferous limestones from the Craven Basin of northern England. Sedimentology, 22:563-581. 